\title{
Pharmacokinetic equivalence study of nonsteroidal anti-inflammatory drug etoricoxib
}

This article was published in the following Dove Press journal:

Clinical Pharmacology:Advances and Applications

\author{
Raymond R Tjandrawinata' \\ Arini Setiawati ${ }^{2}$ \\ Dwi Nofiarny' \\ Liana W Susanto' \\ Effi Setiawati ${ }^{3}$ \\ 'Dexa Laboratories of Biomolecular \\ Sciences Unit, Dexa Medica Group, \\ Cikarang, West Java, Indonesia; \\ ${ }^{2}$ Department of Pharmacology \\ and Therapeutics, Medical Faculty, \\ University of Indonesia, Jakarta, \\ Indonesia; ${ }^{3}$ Bioavailability and \\ Bioequivalence Laboratory Unit, \\ PT Equilab International, Jakarta, \\ Indonesia
}

Purpose: The current study aimed to evaluate whether a generic product of etoricoxib $120 \mathrm{mg}$ film-coated tablet (the test drug) was bioequivalent to the reference product (Arcoxia ${ }^{\circledR}$ filmcoated tablet $120 \mathrm{mg}$ ).

Methods: This was a randomized, open-label, two-sequence, crossover study under fasting condition, with a 14-day washout period, involving 26 healthy adult male and female subjects. Blood samples were taken and analyzed for plasma concentrations of etoricoxib (Chemical Abstracts Service [CAS] 202409-33-4) using a high-pressure liquid chromatography-ultraviolet detector (HPLC-UV) system capable of measuring etoricoxib concentrations ranging from 5.00 to $5002.90 \mathrm{ng} / \mathrm{mL}$, with the lowest limit of quantitation of $5.00 \mathrm{ng} / \mathrm{mL}$. A noncompartmental method was used to determine the pharmacokinetic parameters of a single-dose administration of the drug, including the area under plasma concentration-time curve from time zero to the time of last observed concentration $\left(\mathrm{AUC}_{0-t}\right)$, the area under plasma concentration-time curve from time zero to infinity $\left(\mathrm{AUC}_{0-\infty}\right)$, the maximum plasma concentration $\left(C_{\max }\right)$, the time to reach the maximum plasma concentration $\left(t_{\max }\right)$, and the terminal half-life $\left(t_{1 / 2}\right)$.

Results: After a single-dose administration of etoricoxib $120 \mathrm{mg}$ film-coated tablet, the mean (SD) values for the $\mathrm{AUC}_{0-72 \mathrm{~h}}$ and $C_{\max }$ of the test drug were $45913.42(13142.19) \mathrm{ng} \cdot \mathrm{h} / \mathrm{mL}$ and 3155.93 (752.81) $\mathrm{ng} / \mathrm{mL}$, respectively; the values for the reference drug were 44577.20 (13541.85) $\mathrm{ng} \cdot \mathrm{h} / \mathrm{mL}$ and $2915.13(772.81) \mathrm{ng} / \mathrm{mL}$, respectively. The geometric mean ratios (90\% CIs) of the test drug/reference drug were $103.40 \%(98.70 \%-108.32 \%)$ for $\mathrm{AUC}_{0-72 \mathrm{~h}}$ and $109.26 \%(100.18 \%-119.18 \%)$ for $C_{\max }$. No clinically significant differences in $t_{\max }$ and $t_{1 / 2}$ values were found between the test drug and the reference drug. No adverse events were experienced by the subjects during this study.

Conclusion: The present study demonstrated that the evaluated generic etoricoxib $120 \mathrm{mg}$ film-coated tablets were bioequivalent to the reference drug.

Keywords: bioavailability, bioequivalence, etoricoxib, nonsteroidal anti-inflammatory drug, selective cyclooxygenase- 2 inhibitor

\section{Introduction}

It has been estimated that about a quarter to two-thirds of the health budget in developing countries is spent on medication. ${ }^{1}$ Provision of generic medications is currently the most cost-saving strategy for addressing the lack of access to medications. ${ }^{2}$ Generic medications should follow the quality guidelines, as well as the nonclinical and clinical requirements, issued by the health authorities. ${ }^{3,4}$ The active ingredients of generic medications are identical to those of the originator medications, but the generics are definitely much more affordable than the originator products. Generics are generally
Correspondence: Raymond R Tjandrawinata

Dexa Laboratories of Biomolecular Sciences Unit, Dexa Medica Group, Industri Selatan V Block PP No 7 , Jababeka Industrial Estate II, Cikarang,

West Java 17550, Indonesia

Tel +62 2189841901

Fax +622189841905

Email raymond@dexa-medica.com 
permitted to enter the market only when the patent for the originator has lapsed. ${ }^{5}$

The global regulatory requirement for equivalent bioavailability, or the so-called bioequivalence, of generic medicinal products has become crucial in medicine and pharmaceutical development over the past three decades. Bioavailability is defined as the rate and extent to which the pharmaceutical ingredient or active moiety is absorbed from a drug product and becomes available in the systemic circulation. The extent of absorption is indicated by the area under the concentration versus time curve (AUC), and the rate of absorption is reflected by the time to reach the peak concentration $\left(t_{\max }\right)$, while both the extent and the rate of absorption together are represented by the peak concentration $\left(C_{\max }\right) \cdot{ }^{6,7}$ Two pharmaceutical equivalents or pharmaceutical alternatives are regarded bioequivalent or pharmacokinetically equivalent when both are administered at the same molar dose under standardized conditions in an appropriately designed study and show no significant difference in the rate and extent of their absorption, thus providing similar levels of the active ingredient or active moiety that is available at the site of drug action. In brief, the two medicinal products show a similar or equivalent bioavailability. ${ }^{8}$ Based on that understanding, two formulations that are bioequivalent may consequently be claimed to have essentially the same therapeutic qualities; or, in other words, they are therapeutically equivalent. This means that both formulations possess beneficial and adverse effects that are essentially the same, and hence, they are interchangeable. ${ }^{7-9}$

Etoricoxib (Chemical Abstracts Service [CAS] 20240933-4) is described chemically as 5-chloro-6'-methyl-3-[4(methylsulfonyl)phenyl]-2,3'-bipyridine. The empirical formula is $\mathrm{C}_{18} \mathrm{H}_{15} \mathrm{ClN}_{2} \mathrm{O}_{2} \mathrm{~S}$. The molecular weight is 358.84 . Etoricoxib is a white-to-off-white powder that is practically insoluble in water ${ }^{10}$ and has the structural formula shown in Figure 1.

Etoricoxib is classified as a cyclooxygenase (COX)-2 inhibitor, a relatively new class of nonsteroidal antiinflammatory drugs (NSAIDs). The drug is clinically indicated for alleviation of pain and inflammation associated with rheumatoid arthritis (RA), osteoarthritis (OA), ankylosing spondylitis, and acute gouty arthritis, with minimal gastrointestinal adverse effects. ${ }^{10,11}$ The oral bioavailability of etoricoxib is not affected by food or high-fat meal, and thus, the drug can be administered with or without food. After oral dosing, etoricoxib is well absorbed, with absolute bioavailability of $\sim 100 \%{ }^{10,11}$ Around $92 \%$ of the administered oral dose of etoricoxib is bound to human plasma protein.

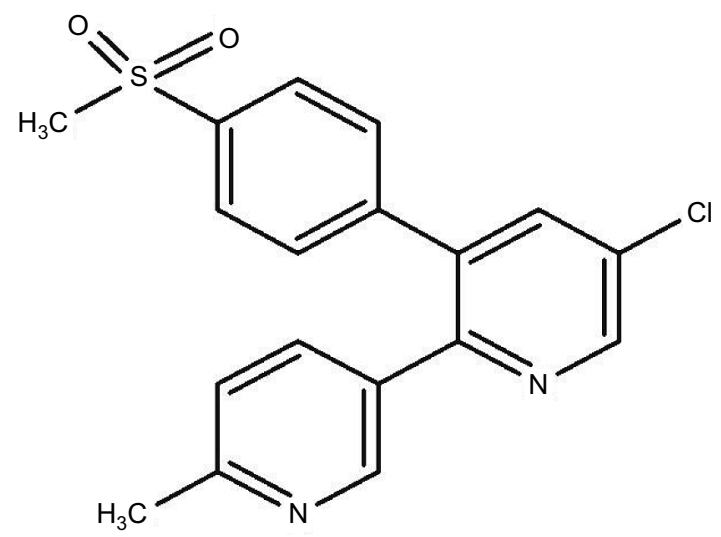

Figure I Chemical structure of etoricoxib.

Etoricoxib is extensively metabolized, with only $<1 \%$ recovered as the parent drug in urine. The drug metabolites are primarily $(\sim 70 \%)$ recovered in urine and $\sim 20 \%$, in the feces. The half-life of etoricoxib is $\sim 22$ hours. ${ }^{11}$ The most commonly reported adverse reactions in clinical trials were fatigue, dizziness, edema, upper respiratory tract infection, hypertension, diarrhea, epigastric discomfort, heartburn, nausea, sinusitis, headache, and urinary tract infection. ${ }^{11}$

This study was conducted to find out whether the bioavailability of the generic etoricoxib $120 \mathrm{mg}$ film-coated tablet formulation produced by PT Dexa Medica, Palembang, Indonesia, was equivalent to that of the reference drug, which is the originator product of etoricoxib.

\section{Methods}

\section{Study subjects and design}

Before study commencement, the protocol, patient information, and consent form were reviewed and approved by the Ethics Committee of the Faculty of Medicine, the University of Indonesia, as well as the National Agency of Drug and Food Control of Indonesia. Each study subject voluntarily gave a written informed consent prior to screening. The conduct of the study conformed to the Declaration of Helsinki, ${ }^{12}$ Good Clinical Practice, ${ }^{13}$ Good Laboratory Practice, ${ }^{14}$ and the relevant regulatory requirements. ${ }^{6,7,15}$

This study was a randomized, open-label, two-sequence, crossover study, under fasting condition, with 14 days of washout period; it involved 26 healthy subjects. Medical examination of the study subjects was performed within 14 days prior to their first dosing day. The assessment included the following: physical examination; recording of vital signs (blood pressure, pulse rate, respiratory rate, and temperature), electrocardiography, and laboratory assessment on routine hematology (hemoglobin, hematocrit, erythrocyte 
count, as well as platelet and leukocyte count); determination of liver function (serum levels of alkaline phosphatase, alanine aminotransferase, aspartate aminotransferase, and total bilirubin) and renal function (serum creatinine and urea); blood glucose estimation; immunological tests for hepatitis B surface antigen (HBsAg) and anti-hepatitis C virus (HCV) and anti-human immunodeficiency virus (HIV) antibodies; and routine urinalysis (determination of $\mathrm{pH}$, glucose level, protein level, and urine sediments). Pregnancy test (for women) was also performed at screening and before introducing the drug in each period.

A set of inclusion and exclusion criteria were required and followed to ensure that the recruited study subjects were free of accompanying diseases interfering with the conduct and scientific evaluation of the study. Male or female subjects between 18 and 55 years of age who had normal range of body mass index of $18-25 \mathrm{~kg} / \mathrm{m}^{2}$, normal blood pressure and pulse rate, and signed the informed consent were recruited to participate in this study. Subjects with any of the following criteria were excluded: pregnant women and nursing mothers; persons with known contraindications or hypersensitivity to etoricoxib or allied drugs; any major illness in the past 90 days or clinically significant ongoing chronic medical illness - eg, congestive cardiac failure (heart failure), hepatitis, hypotensive episodes, hyperglycemia, chronic gastrointestinal disorders, and liver dysfunction; clinically significant electrocardiogram or hematology abnormalities; renal insufficiency; positive test results for $\mathrm{HBsAg}$, anti$\mathrm{HCV}$, and/or anti-HIV antibodies; any surgical or medical condition (present or historical) that might significantly alter the absorption, distribution, metabolism, or excretion of the study drug; past history of anaphylaxis or angioedema; history of drug or alcohol abuse within 12 months prior to screening; history of any bleeding or coagulation disorders; history of difficulty in donating blood or in accessibility of veins in left or right arm; a donation or loss of $300 \mathrm{~mL}$ (or more) of blood within the past 3 months; intake of any prescription or nonprescription drug, food supplements, or herbal medicines within 14 days of the first dosing day of the study; or participation in any interventional clinical trial within the past 90 days.

\section{Study products}

The generic drug investigated as the test drug in the study was etoricoxib $120 \mathrm{mg}$ film-coated tablets produced by PT Dexa Medica, Palembang, Indonesia, and the reference drug used as the comparator in this study was Arcoxia ${ }^{\circledR} 120 \mathrm{mg}$ filmcoated tablet (Frosst Iberica SA, Madrid, Spain, for Merck
Sharp \& Dohme [Australia] Pty Limited, NSW, Australia; registered by PT Schering-Plough Indonesia Tbk, Jakarta, Indonesia).

\section{Clinical and analytical procedures}

In this crossover study, each subject was assigned to the test drug $\mathrm{T}$ and the reference drug $\mathrm{R}$ following two sequences ( $\mathrm{TR}$ and RT). Using block randomization with a block size of 4 , the six permutations obtained were assigned numbers $1-6$, which then were scrambled based on the Table of Random Numbers proposed by Dixon and Massey. ${ }^{16}$ The study drugs were prepared prior to the dosing day by an independent person who had qualified as a pharmacist.

Subjects arrived at the study site a night before drug administration, and they were requested to fast from any food and drink, except mineral water, for 10 hours. After the overnight fast, a predose pharmacokinetic blood sample was taken on the morning of the dosing day (Day 1). Subsequently, one single dose of the study drug (either the test or the reference drug) was given to be swallowed with $200 \mathrm{~mL}$ of water, without chewing. The date and time of study drug administration were recorded in the case report form. The subjects were provided with standardized lunch and dinner at 4 and 10 hours after study drug administration, respectively. Moreover, the amount of food intake and the physical activity for each individual subject were also standardized during the sampling days. Fruit juices and xanthine-containing food or beverages were not allowed for 24 hours before and during the entire sampling days.

Venous blood samples were drawn immediately before dosing with the drug (at baseline; $10 \mathrm{~mL}$ ) and at 15, 30, and 45 minutes as well as 1, 1.5, 2, 3, 4, 6, 8, 12, 18, 24, 36, 48, and 72 hours ( $5 \mathrm{~mL}$ each) after drug administration. After a 14-day washout period, the same procedure was repeated with the alternate drug. The blood samples collected at each time point from all subjects were centrifuged at $1538 \times g$ (radius of rotor $=86 \mathrm{~mm}$ ) for 15 minutes to separate the plasma, and then the plasma was transferred to a clean tube. Plasma samples were stored in a freezer at $-20^{\circ} \mathrm{C} \pm 5^{\circ} \mathrm{C}$ at the clinical site until they were transferred to the analytical site for measurement of the drug concentrations.

The following procedures were applied for the extraction of samples from the subjects, calibration of quality control standards, and comparisons. After thawing, the plasma sample was dispensed in an appropriate tube, and then tertbutyl methyl ether was added as the solvent. The content of the tube was vortexed and centrifuged. The supernatant was transferred to a vial and injected into a high-performance 
liquid chromatography (HPLC) system with ultraviolet (UV) detector (HPLC-UV) (Water Alliance 2695; Waters Corporation, Milford, MA, USA) under the following conditions: Sunfire $5 \mu \mathrm{m}$ C18 column of dimensions $4.6 \times 150 \mathrm{~mm}$; Phenomenex $\mathrm{C} 18$ as guard column, with UV detector at a wavelength of $284 \mathrm{~nm}$; an injection volume of $50 \mu \mathrm{L}$; a flow rate of $1.2 \mathrm{~mL} / \mathrm{min}$; and a mobile phase of acetonitrile:water (42:58). Calibration standards, controls, and samples were processed in batches.

All chromatograms in the same batch were processed automatically with the help of software using the same processing parameters, such as integration, peak-to-peak amplitude, and peak detection. Manual integration was performed only when necessary.

The etoricoxib concentrations in plasma samples were assayed using a fully validated HPLC-UV method, in terms of adequate sensitivity, specificity, linearity, accuracy, and precision (both within and between days). The stability of the samples under frozen conditions, at room temperature, and during freeze-thaw cycles was also determined. The validation data presented in Table 1 were taken from our validation report. The chromatograms obtained from the analytical validation of etoricoxib using valdecoxib as internal standard are provided in Figure 2.

The calibration curve was prepared by least-squares linear regression: $Y=\mathrm{a} X+\mathrm{b}$, where $X$ is the concentration of etoricoxib and $Y$ is the peak area ratio of etoricoxib to internal standard. The internal standard used was valdecoxib. The concentration of etoricoxib in the plasma sample was determined by entering the peak area ratio of etoricoxib to internal standard into the regression equation of the standard calibration curve. If a sample had a predicted concentration below the limit of quantitation, its value was not extrapolated and was reported as below quantitation limit, even if the analyte was detectable. Likewise, estimation of the concentration in a sample by extrapolation of the standard curve above the upper limit was not allowed. Instead, the sample was diluted using blank human plasma, then the diluted sample was assayed, and the corresponding value was calculated and reported.

\section{Pharmacokinetic parameters}

The standard noncompartmental method was used for determination of pharmacokinetic parameters. Plasma concentration-time data were analyzed, and the pharmacokinetic parameters derived were as follows: the area under plasma concentration-time curve from time zero to the time of last observed concentration ( 72 hours; $\mathrm{AUC}_{0-72 \mathrm{~h}}$ ), the area under plasma concentration-time curve from time zero to infinity $\left(\mathrm{AUC}_{0-\infty}\right)$, the maximum plasma concentration $\left(C_{\max }\right)$, the time to reach the maximum plasma concentration $\left(t_{\max }\right)$, and the terminal half-life $\left(t_{1 / 2}\right)$. The $C_{\max }$ and $t_{\max }$ were obtained directly from the observed data, while $\mathrm{AUC}_{0-72 \mathrm{~h}}$ was calculated by the trapezoidal method. $\mathrm{AUC}_{0-\infty}$ was calculated as the sum of $\mathrm{AUC}_{0-72 \mathrm{~h}}$ and $C_{72 \mathrm{~h}} / k_{\mathrm{e}}$, where $C_{72 \mathrm{~h}}$ - the plasma concentration of the drug at 72 hours - was obtained from the observed data, and $k_{\mathrm{e}}$ - the terminal elimination rate constant - was determined by least-squares regression analysis during the terminal log-linear phase of the concentration-time curve. ${ }^{8}$ The $t^{1} / 2$ was calculated as $0.693 / k_{\mathrm{e}}$. In this study, the

Table I The validation data of the analytical method used for determination of etoricoxib in human plasma by HPLC-UV using valdecoxib as the internal standard

\begin{tabular}{|c|c|c|c|c|c|}
\hline \multirow[t]{2}{*}{ Parameters } & \multirow[t]{2}{*}{ Conditions } & \multicolumn{4}{|l|}{ Concentration } \\
\hline & & $\begin{array}{l}\text { LLoQ } \\
(5.00 \mathrm{ng} / \mathrm{mL})\end{array}$ & $\begin{array}{l}\text { Low } \\
(15.00 \mathrm{ng} / \mathrm{mL})\end{array}$ & $\begin{array}{l}\text { Medium } \\
(802.22 \mathrm{ng} / \mathrm{mL})\end{array}$ & $\begin{array}{l}\text { High } \\
(2000.56 \mathrm{ng} / \mathrm{mL})\end{array}$ \\
\hline \multirow[t]{2}{*}{ Precision $^{\mathrm{a}}$} & Intra-assay CV & $12.07 \%$ & $11.42 \%$ & $5.88 \%$ & $3.10 \%$ \\
\hline & Interassay CV & $10.08 \%$ & $11.56 \%$ & $7.29 \%$ & $4.51 \%$ \\
\hline \multirow[t]{2}{*}{ Accuracy ${ }^{b}$} & Intra-assay CV & $-1.50 \%$ & $6.44 \%$ & $1.75 \%$ & $-0.10 \%$ \\
\hline & Interassay CV & $7.93 \%$ & $2.72 \%$ & $-3.27 \%$ & $-3.49 \%$ \\
\hline Stability, with & At $-20^{\circ} \mathrm{C} \pm 5^{\circ} \mathrm{C}$ : stable until 83 days & - & $-10.17 \%$ to $10.83 \%$ & - & $1.95 \%-10.46 \%$ \\
\hline \multirow[t]{3}{*}{ accuracy ${ }^{\mathrm{b}}$} & $\begin{array}{l}\text { At room temperature: stable until } \\
6 \text { hours }\end{array}$ & - & $-10.17 \%$ to $10.40 \%$ & - & $1.95 \%-9.29 \%$ \\
\hline & Freeze-thaw process: stable until & - & $-8.15 \%$ to $4.35 \%$ & - & $1.13 \%-5.16 \%$ \\
\hline & 3 cycles & & & & \\
\hline Selectivity & \multicolumn{5}{|c|}{$\begin{array}{l}\text { The chromatograms showed no interfering substances of the lowest concentration in } 6 \text { replicates of blank plasma; the CV for the } \\
\text { lowest concentration was } 4.07 \% \text {. }\end{array}$} \\
\hline
\end{tabular}



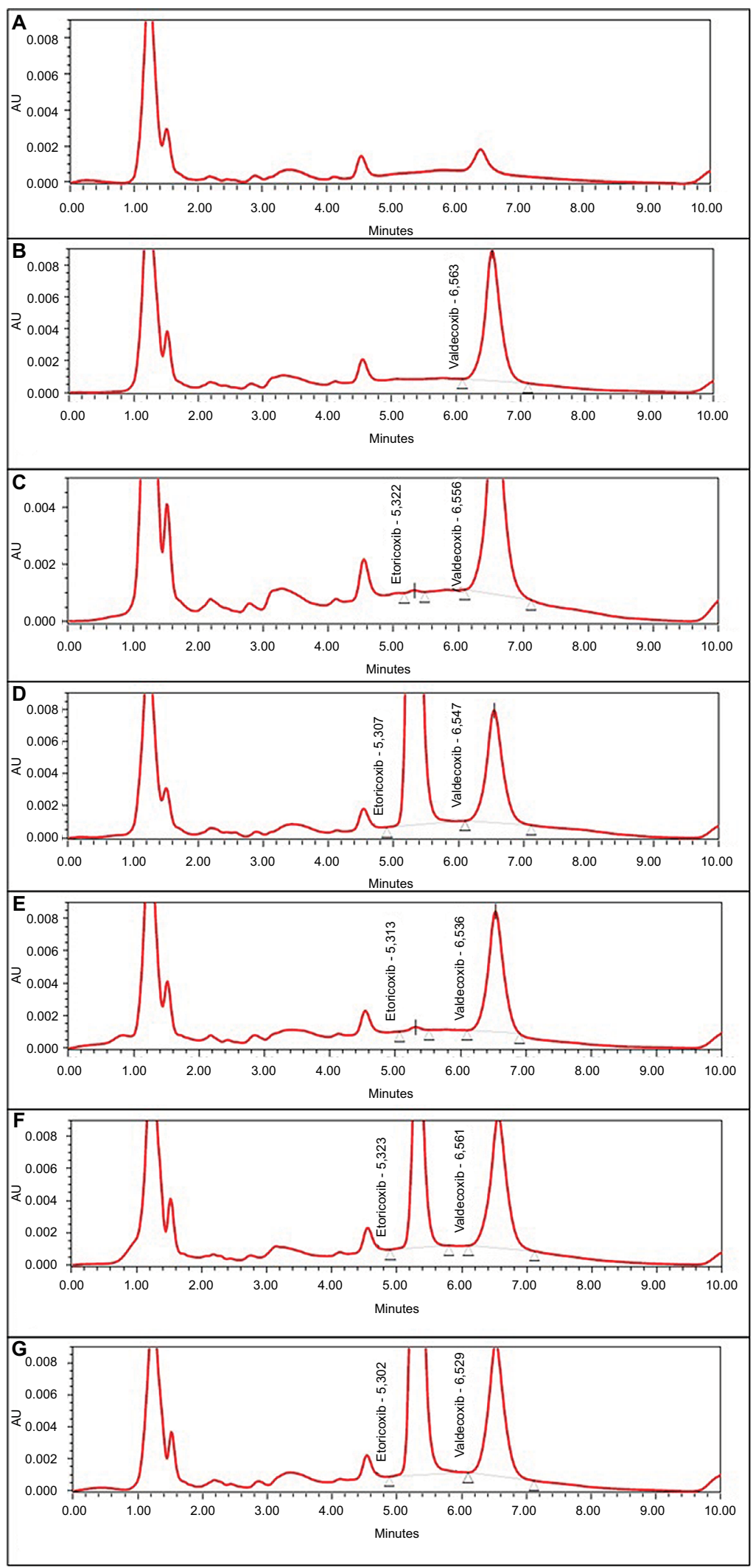

Figure 2 Chromatograms from the analytical validation to determine etoricoxib in human plasma by HPLC using valdecoxib as the internal standard are shown. Notes: (A) Blank plasma; (B) blank plasma with an internal standard valdecoxib; (C) LLOQ (etoricoxib $5.00 \mathrm{ng} / \mathrm{mL}$ ); (D) the highest standard concentration (etoricoxib $5002.9 \mathrm{ng} / \mathrm{mL}$ ); (E) low QC concentration (etoricoxib $15.00 \mathrm{ng} / \mathrm{mL}$ ); (F) mid QC concentration (etoricoxib $802.22 \mathrm{ng} / \mathrm{mL}$ ); (G) high QC concentration (etoricoxib 2000.56 $\mathrm{ng} / \mathrm{mL}$ ). The retention time of etoricoxib in the validated HPLC system was $\sim 5.3$ minutes; with valdecoxib as the internal standard, retention was $\sim 6.5$ minutes.

Abbreviations: AU, absorbance units; HPLC, high-performance liquid chromatography; LLOQ, lowest limit of quantitation; QC, quality control. 
sampling period was spanned up to 72 hours, which is $>3$ times the half-life of etoricoxib.

\section{Statistical analysis}

Phoenix ${ }^{\circledR}$ WinNonlin version 6.4 (Certara LP, St Louis, MO, USA) was used to perform statistical analyses of the $\mathrm{AUC}_{0-72 \mathrm{~h}}, \mathrm{AUC}_{0-\infty}$, and $C_{\text {max }}$ by analysis of variance (ANOVA) after transformation of the data to their natural logarithmic $(\ln )$ values. The statistical power of the study would be $80 \%$ at the minimum, with $\alpha$ of $5 \%$ (two-sided). According to the European Medicines Agency (EMA) Guideline on the Investigation of Bioequivalence, the acceptance criteria for bioequivalence are that the $90 \%$ CIs of the geometric mean ratio for the $\mathrm{AUC}_{0-t}$ and $C_{\max }$ should be between 0.80 and $1.25 .^{7}$ The difference in $t_{\max }$ in the original data was analyzed nonparametrically using Wilcoxon matched-pairs test. The difference in $t_{1 / 2}$ was analyzed using the Student's paired $t$-test or the Wilcoxon matched-pairs test depending on whether the differences in the paired data were normally distributed.

\section{Results}

All the 26 enrolled subjects completed the study, and their blood samples were analyzed for the pharmacokinetic evaluation of etoricoxib. Of them, 18 (69.2\%) and $8(30.8 \%)$ were male and female subjects, respectively, with age ranging between 19 and 51 years, and the body mass index ranging between 18.04 and $24.59 \mathrm{~kg} / \mathrm{m}^{2}$. The summary of the pharmacokinetic parameters after administration of a single oral dose of the test drug ( $\mathrm{T}$; generic etoricoxib $120 \mathrm{mg}$ film-coated tablet) and the reference drug $(\mathrm{R})$ is shown in Table 2 , and the pharmacokinetic profiles are provided in Figure 3. Statistical calculations for $\mathrm{AUC}_{0-72 \mathrm{~h}}, \mathrm{AUC}_{0-\infty}$, and $C_{\max }$ were based on the ln-transformed data. The calculated $90 \%$ CIs of the test/ reference geometric mean ratios are also presented in Table 2 . The actual statistical power of the study was calculated by the statistical program and is shown in Table 2.

Table 2 also shows that the mean (SD) elimination halflives $\left(t^{1 / 2}\right)$ of etoricoxib were 20.95 (10.91) hours and 20.69 (8.40) hours for the test and the reference drugs, respectively. The median (range) values of the time to reach the maximum plasma concentration $\left(t_{\max }\right)$ of etoricoxib were $1.00(0.50-4.00)$ hour and $1.00(0.75-4.00)$ hour for the test and reference drugs, respectively.

No adverse event occurred during the conduct of the study.

\section{Discussion}

The objective of this study was to evaluate whether a generic etoricoxib $120 \mathrm{mg}$ film-coated tablet is bioequivalent to the reference drug and thus of therapeutic equivalence. In order to obtain the answer, a bioequivalence study based on pharmacokinetic end points was preferable to a pharmacodynamic or clinical end point study. This is particularly relevant because the extent of absorption of etoricoxib film-coated tablet is sufficient for direct measurement of the drug concentration in plasma, and its plasma concentration has a good correlation with the therapeutic effect of the drug. ${ }^{9,17}$ Such a bioequivalence study is critically required by the regulatory or health authorities in most countries for abbreviated new drug application (ANDA) submission of a generic product. A generic medicinal product demonstrating its bioequivalence to the reference product indicates its therapeutic equivalence as well; thus, any comparative clinical safety and efficacy studies are no more required for that particular generic. In this regard, selection of the reference product becomes critically important. The safety and efficacy of reference products should have been established through

Table 2 Pharmacokinetic parameters of etoricoxib $(\mathrm{N}=26)$ after a single-dose oral administration of 120 mg etoricoxib film-coated tablets (test drug, $\mathrm{T}$ ) and the reference drug (R)

\begin{tabular}{|c|c|c|c|c|c|}
\hline \multirow[t]{2}{*}{ Parameter } & \multicolumn{2}{|l|}{ Mean (SD) } & \multirow{2}{*}{$\begin{array}{l}\text { Geometric mean ratio } \\
\text { of } T / R(90 \% \mathrm{Cl})^{\mathrm{a}}\end{array}$} & \multirow{2}{*}{$\begin{array}{l}\text { \% intrasubject } \\
\mathrm{CV}\end{array}$} & \multirow{2}{*}{$\begin{array}{l}\text { Statistical } \\
\text { power (\%) }\end{array}$} \\
\hline & Test & Reference & & & \\
\hline $\mathrm{AUC}_{0-72 \mathrm{~h}}(\mathrm{ng} \cdot \mathrm{h} / \mathrm{mL})^{\mathrm{b}}$ & $45913.42(13142.19)$ & $44577.20(13541.85)$ & $103.40 \%(98.70 \%-108.32 \%)$ & 9.83 & 99.99 \\
\hline $\mathrm{AUC}_{0-\infty}(\mathrm{ng} \cdot \mathrm{h} / \mathrm{mL})^{\mathrm{b}}$ & $51521.71(18110.05)$ & 49333.14 (16969.72) & $104.14 \%(99.29 \%-109.24 \%)$ & 10.10 & 99.99 \\
\hline$C_{\max }(\mathrm{ng} / \mathrm{mL})^{\mathrm{b}}$ & $3155.93(752.81)$ & $2915.13(772.81)$ & $109.26 \%(100.18 \%-119.18 \%)$ & 18.46 & 98.35 \\
\hline$t_{1 / 2}$ (hours) & $20.95(10.91)$ & $20.69(8.40)$ & $N S^{c}$ & - & - \\
\hline$t_{\max }$ (hours) $^{\mathrm{d}}$ & $1.00(0.40-2.00)$ & $1.00(0.75-4.00)$ & $0.018^{e}$ & - & - \\
\hline
\end{tabular}

Notes: aBioequivalence criteria are defined as $90 \%$ Cls of the geometric mean ratios of T/R lying between $80.00 \%$ and $125.00 \%$ for AUC ${ }_{0.72 h}$ and $C_{\text {max }}$; ${ }^{\text {bstatistical calculations }}$ for AUC and $C_{\max }$ were based on In-transformed data; ' analysis was performed by Student's paired $t$-test; ${ }^{d}$ the values are expressed in median (range); ${ }^{\mathrm{e}}$ analysis was performed by Wilcoxon matched-pairs test.

Abbreviations: $\mathrm{AUC}_{0-\mathrm{t}}$, area under the plasma concentration-time curve from time zero to the time of last observed concentration (72 hours or infinity); $C_{\text {max }}$, the maximum plasma concentration; $\mathrm{CV}$, coefficient of variation; In, natural logarithm; $t_{1 / 2}$, terminal half-life; $t_{\max }$, time to the maximum plasma concentration; NS, not significant. 


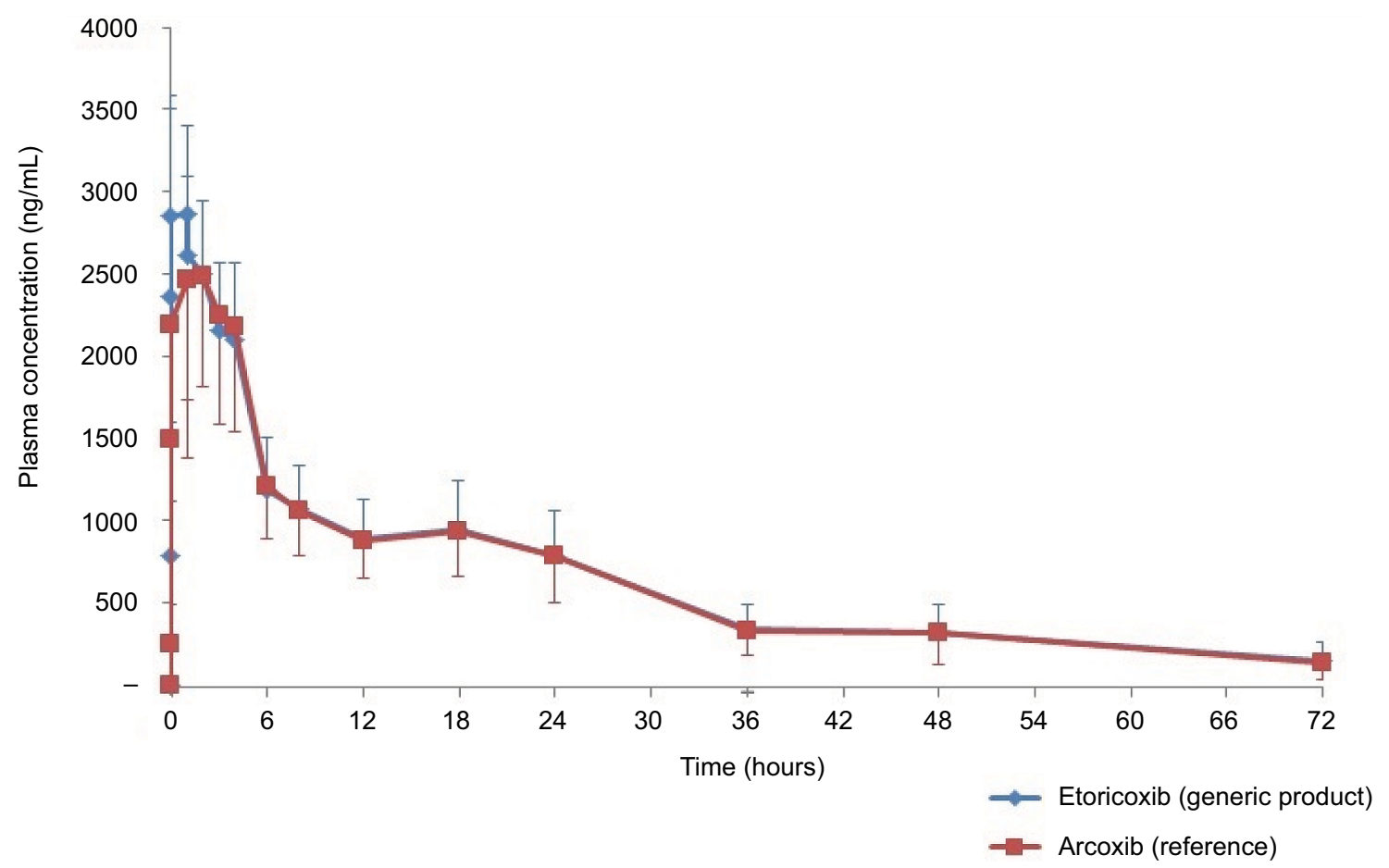

Figure 3 Mean plasma concentration-time profiles of etoricoxib in human subjects $(\mathrm{N}=26)$ after a single-dose oral administration of generic etoricoxib I20 mg film-coated tablets (test drug) and the reference drug.

Note: The error bars indicate standard deviation (SD).

a series of preclinical and clinical trials. ${ }^{18,19}$ In addition, the results of the bioequivalence study of a particular generic are not applicable to other pharmaceutical equivalents (other generic medicinal products with identical active substance, same dosage form, as well as same route of administration and strength). This underlined the necessity of the present study despite the availability of bioequivalence studies on previously available generic etoricoxib products. ${ }^{20,21}$

Further, a reliable bioequivalence study should be performed in order to ensure that a generic medicine possesses similar quality as its reference, which is usually the innovator's (originator) product, in terms of safety and efficacy. Therefore, a generic medicinal product should be produced at more economical costs, but without compromising the quality. Providing generic medicinal products supports pharmacoeconomics, which benefits both patients and health care professionals, since they have options to select quality medications at affordable price..$^{22,23}$

This was a randomized, open-label, two-period, twosequence, crossover study under fasting condition, which included 26 healthy adult male and female subjects and which aimed to compare the bioavailability of a generic, etoricoxib $120 \mathrm{mg}$ film-coated tablet, relative to the reference drug. All the 26 study subjects were compliant with the inclusion/exclusion criteria of the study and completed the study. Unless it is against ethical principles, inclusion of healthy subjects is scientifically required for conducting a bioequivalence study. This is mainly intended to minimize pharmacokinetic variability associated with any concomitant illnesses and medications taken by the study subjects.

Following the general recommendation in many regulatory guidelines for bioavailability and bioequivalence studies, the test and reference drugs in this study were given as a single dose because it is generally more sensitive than a multiple-dose administration in assessing the release of the active substance from the drug product. ${ }^{6,8,24}$ The etoricoxib film-coated tablets can be administered orally without regard to food intake; ${ }^{11}$ thus, this study was recommended to be conducted under fasting condition as this is the most sensitive condition to detect a potential difference between formulations. $^{\text {? }}$

For comparison of the extent of drug exposure, the final sampling was done at 72 hours, which is $>3$ times the halflife of etoricoxib ( $\sim 22$ hours). With a sampling period of $>3$ half-lives of the drug, the $\mathrm{AUC}_{0-72 \mathrm{~h}}$ covered $>87.5 \%$ of the $\mathrm{AUC}_{0-\infty}$. This met the EMA guideline that requires the $\mathrm{AUC}_{0-t}$ to cover at least $80 \%$ of the $\mathrm{AUC}_{0-\infty 0^{\circ}}{ }^{7}$ The $\mathrm{AUC}_{0-72 \mathrm{~h}}$ and $C_{\text {max }}$ 
of etoricoxib were defined as the main parameters in order to assess the possible bioequivalence between both preparations. The present study demonstrated that the $90 \%$ CIs of the test/reference geometric mean ratios for $\mathrm{AUC}_{0-t}$, as well as the $C_{\max }$, of etoricoxib were within the acceptable range of bioequivalence $(80.00 \%-125.00 \%)$.

This study also reported the comparisons of other pharmacokinetic parameters: $t_{\max }$ and $t_{1 / 2}$. The median (range) values of the time to reach the maximum plasma concentration $\left(t_{\max }\right)$ of etoricoxib were $1.00(0.50-4.00)$ hour and $1.00(0.75-4.00)$ hour for the test and reference drugs, respectively. Using Wilcoxon matched-pairs test on the original data, the difference in $t_{\text {max }}$ values between the two drugs (test and reference drugs) was statistically significant. Clinically, however, the difference was not meaningful since both the test and reference drugs reached the maximum concentration at $\sim 1$ hour after administration to the fasted adult subjects, which also aligned with the value reported in the summary of product characteristics of etoricoxib. ${ }^{11}$ In addition, there is no known evidence reporting the clinical importance of $t_{\max }$ in relation to the activity (such as onset of action) of etoricoxib immediate-release (IR) formulations. Finally, for IR products, the difference in $t_{\text {max }}$ values (between the generic and reference products) is not taken into consideration while determining bioequivalence. The pharmacokinetic parameters determining bioequivalence according to the EMA Guideline on the Investigation of Bioequivalence consist of the $\mathrm{AUC}_{0-\mathrm{t}}$ and $C_{\max }$ only. ${ }^{7}$

The mean (SD) elimination half-lives $\left(t^{1} / 2\right)$ of etoricoxib were 20.95 (10.91) hours and 20.69 (8.40) hours for the test drug and the reference drug, respectively. Utilizing Student's paired $t$-test, the half-life values of the test and reference drugs were not significantly different, demonstrating a comparable rate of drug elimination from the body.

In order to perform the two one-sided $t$-test procedures for bioequivalence for the ln-transformed etoricoxib plasma concentration data within the bioequivalence limits of 0.8 and 1.25 , with a value of $\alpha=0.05$ and power $=80 \%$, the number of subjects needed for the bioequivalence study with crossover design was based on calculation and the table provided in a previous publication. ${ }^{25}$ In the present study, the intrasubject coefficient of variance $(\% \mathrm{CV})$ obtained from the ANOVA for the etoricoxib $\mathrm{AUC}_{0-72 \mathrm{~h}}$ was $9.83 \%$, and hence, the number of subjects in this study (26 subjects) was sufficient to ensure an adequate statistical power required for a valid and reliable study conclusion. ${ }^{25,26}$

Neither minor nor major adverse event was observed during the study period.

\section{Conclusion}

The present study concluded that the evaluated generic etoricoxib $120 \mathrm{mg}$ film-coated tablets were bioequivalent to the reference drug.

\section{Acknowledgments}

This study was funded by Dexa Medica. The authors deeply thank all volunteers for their participation in this study.

\section{Author contributions}

RRT, AS, and ES provided the study concept and design, and critically reviewed the intellectual content of the manuscript. ES supervised the conduct of the study and was responsible for the management of study subjects and data. AS, DN, and ES interpreted the study data, and LWS prepared the draft manuscript. The authors and sponsor agreed to maintain the confidentiality of the data. All authors had access to the data and assume responsibility for the integrity and completeness of the reported data. All authors contributed toward data analysis, drafting and revising the paper and agree to be accountable for all aspects of the work. The corresponding author made the decision to submit the manuscript for publication.

\section{Disclosure}

The authors report no conflicts of interest in this work.

\section{References}

1. WHO [webpage on the Internet]. World Health Organization Essential Medicines and Health Products; 2017. Available from: www.who.int/ medicines/services/essmedicines_def/en/.Accessed December 18, 2017.

2. FDA. Facts about Generic Drugs; 2016. Available from: www.fda. gov/downloads/drugs/resourcesforyou/consumers/buyingusingmedicinesafely/understandinggenericdrugs/ucm305908.PDF. Accessed December 18, 2017.

3. EMA [webpage on the Internet]. Generic and Hybrid Medicines; 2012. Available from: www.ema.europa.eu/ema/index.jsp?curl=pages/ special_topics/document_listing/document_listing_000335. jsp\&mid=WC0b01ac0580514d5c. Accessed December 18, 2017.

4. FDA [webpage on the Internet]. Generic Drugs; 2017. Available from: https://www.fda.gov/drugs/resourcesforyou/consumers/buyingusingmedicinesafely/genericdrugs/default.htm. Accessed December 18, 2017.

5. Danta M, Ghinea N. The complex legal and ethical issues related to generic medications. Viral hepatitis: a case study. J Virus Erad. 2017;3(2):77-81.

6. BPOM. Badan Pengawas Obat dan Makanan Republik Indonesia. Pedoman Uji Bioekivalensi [Guideline for Bioequivalence Studies]; 2004. Available from: http://jdih.pom.go.id/produk/PERATURAN\%20 KEPALA\%20BPOM/PER\%20KBPOM_NO.HK.00.05.3.1818\%20 TH\%202005_Tentang\%20PEDOMAN\%20UJI\%20BIOEKIV_2005. pdf. Accessed December 18, 2017.

7. EMA. Committee for Medicinal Products for Human Use (CHMP) European Medicines Agency. Guideline on the investigation of bioequivalence. CPMP/EWP/QWP/1401/98 Rev. 1; 2010. Available from: http://www.ema.europa.eu/docs/en_GB/document_library/Scientific_ guideline/2010/01/WC500070039.pdf. Accessed December 4, 2017. 
8. FDA. US Department of Health and Human Services Food and Drug Administration Center for Drug Evaluation and Research (CDER). Guidance for industry: bioavailability and bioequivalence studies for orally administered drug products-General considerations; 2003. Available from: https://www.fda.gov/ohrms/dockets/ac/03/ briefing/3995B1_07_GFI-BioAvail-BioEquiv.pdf. Accessed December 18,2017

9. FDA. US Department of Health and Human Services Food and Drug Administration Center for Drug Evaluation and Research (CDER). Guidance for industry bioequivalence studies with pharmacokinetic endpoints for drugs submitted under an ANDA; 2013. Available from: https://www.fda.gov/downloads/Drugs/GuidanceComplianceRegulatoryInformation/Guidances/UCM377465.pdf. Accessed December 18, 2017.

10. New Zealand Data Sheet. ARCOXIA $®$ (etoricoxib) film coated tablets. WPC-MK0663-T-062015. Merck Sharp \& Dohme (NZ) Ltd.; 24 October 2002, rev. 9 October 2017. Available from: http://www.medsafe.govt nz/profs/datasheet/a/Arcoxiatab.pdf. Accessed December 12, 2017.

11. European Medicines Agency. Scientific evaluation of etoricoxib containing medicinal products. Etoricoxib - Article 31 referral - Annex I, II, III; 2008. Available from: http:/www.ema.europa.eu/docs/en_GB/ document_library/Referrals_document/Etoricoxib_31/WC500011212. pdf. Accessed December 12, 2017.

12. WMA. World Medical Association Declaration of Helsinki. Ethical principles for medical research involving human subjects; 2013. Available from: https:/www.wma.net/wp-content/uploads/2016/11/ DoH-Oct2013-JAMA.pdf. Accessed December 4, 2017.

13. ICH. The International Council for Harmonization of Technical Requirements for Registration of Pharmaceuticals for Human Use. E6 (R2) Integrated Addendum to ICH E6 (R1): Guideline for Good Clinical Practice; 2016. Available from: http://www.ich.org/fileadmin/Public_Web_Site/ ICH_Products/Guidelines/Efficacy/E6/E6_R1_Guideline.pdf. Accessed December 4, 2017.

14. OECD. Environment Directorate Chemicals Group and Management Committee. OECD series on principles of good laboratory practice and compliance monitoring number 1 - OECD principles on good laboratory practice (as revised in 1997); 1998. Available from: http://www. oecd.org/officialdocuments/publicdisplaydocumentpdf $/$ cote $=$ env $/ \mathrm{mc} /$ chem\%2898\%2917\&doclanguage=en. Accessed 4 December 2017.
15. BPOM. Badan Pengawas Obat dan Makanan Republik Indonesia. Pedoman metodologi uji bioekivalensi spesifik zat aktif [Guideline on Methods in Bioequivalence Studies of Specific Active Substances]. Jakarta: BPOM RI; 2011.

16. Dixon WJ, Massey FJ. Introduction to Statistical Analysis. 3rd ed. New York: McGraw-Hill Book Company; 1969.

17. Davit B, Conner D, Shargel L. Chapter 16: drug product performance, in vivo: bioavailability and bioequivalence. In: Shargel L, Yu ABC, editors. Applied Biopharmaceutics \& Pharmacokinetics. 7th ed. McGraw-Hill Education: New York. NY; 2016:469-517.

18. Gwaza L, Gordon J, Leufkens H, Stahl M, Garcia-Arieta A. Global harmonization of comparator products for bioequivalence studies. AAPS J. 2017;19(3):603-606.

19. Kanfer I. Introduction. In: Kanfer I, Shargel L, editors. Generic Drug Product Development: International Regulatory Requirements for Bioequivalence. Vol. 201. Boca Raton, FL: CRC Press. Taylor \& Francis Group; 2016:1-16.

20. Najib ON, Hassan R, Alwadi B, Idkaidek NM, Najib NM. Bioequivalence evaluation of two brands of etoricoxib $120 \mathrm{mg}$ tablets (EtoricoxibSAJA \& ARCOXIA $\left.{ }^{\circledR}\right)$ - in healthy human volunteers. Mod Clin Med Res. 2017;1(1):7-12.

21. Shohag MH, Islam MS, Ahmed MU, et al. Pharmacokinetic and bioequivalence study of etoricoxib tablet in healthy Bangladeshi volunteers. Arzneimittelforschung. 2011;61(11):617-621.

22. Arenas-Guzman R, Tosti A, Hay R, Haneke E; National Institue for Clinical Excellence. Pharmacoeconomics - an aid to better decisionmaking. J Eur Acad Dermatol Venereol. 2005;19(Suppl 1):34-39.

23. Trask LS. Pharmacoeconomics: principles, methods, and applications. In: DiPiro JT, Talbert RL, Yee GC, Matzke GR, Wells BG, Posey M, editors. Pharmacotherapy: A Pathophysiologic Approach. 8th ed. New York: McGraw-Hill Education, LLC; 2011:1-2.

24. Kanfer I, Shargel L, editors. Generic Drug Product Development: International Regulatory Requirements for Bioequivalence. Boca Raton, FL: CRC Press. Taylor \& Francis Group; 2016. Drugs and the Pharmaceutical Sciences; No. 201.

25. Chow SC, Wang H. On sample size calculation in bioequivalence trials J Pharmacokinet Pharmacodyn. 2001;28(2):155-169.

26. Diletti E, Hauschke D, Steinijans VW. Sample size determination for bioequivalence assessment by means of confidence intervals. Int J Clin Pharmacol Ther Toxicol. 1991;29(1):1-8.
Clinical Pharmacology: Advances and Applications

\section{Publish your work in this journal}

Clinical Pharmacology: Advances and Applications is an international, peer-reviewed, open access journal publishing original research, reports, reviews and commentaries on all areas of drug experience in humans. The manuscript management system is completely online and includes a very quick and fair peer-review system, which is all easy to use
Dovepress

Visit http://www.dovepress.com/testimonials.php to read real quotes from published authors.

Submit your manuscript here: https://www.dovepress.com/clinical-pharmacology-advances-and-applications-journal 